3. Simon C, Forde E, Fraser A, et al. What is the root cause of the GP workforce crisis? Br J Gen Pract

4. Barker I, Steventon A, Deeny SR. Association between continuity of care in general practice and hospital admissions for ambulatory care sensitive conditions: cross sectional study of routinely collected, person level data. BMJ 2017; 356: j84.

DOI: https://doi.org/10.3399/bjgp19X700949

\section{Simple techniques for managing dental avulsion in the GP \\ setting}

I read the article investigating why patients might consult GPs for dental problems with great interest. I I recently organised a teaching session for A\&E registrars covering several topics in oral and maxillofacial surgery. A particularly well-received topic was our simple technique for splinting a tooth that has been avulsed (knocked out of its socket). I believe this would be useful knowledge to share with the $B J G P$ readership.

Dental avulsion is a true dental emergency. If such a case presents to a GP, it would be ideal if the tooth is replanted before they are redirected to a dentist. Prompt repositioning and splinting optimises the tooth's prognosis.

The socket and tooth should be gently irrigated with saline, only handling the tooth by the crown (white part). A temporary splint should then be placed in order to immobilise the tooth while the patient seeks dental treatment.

A popular splinting technique involves the application of tissue glue around the tooth. ${ }^{3}$ Even simpler methods include adapting BluTack or aluminium foil to the dental arch. Readers interested in learning more about these techniques are directed to a succinct and well-illustrated article by Beech et al. ${ }^{4}$

Contraindications to replantation are few, but include: replantation of baby teeth (for example, patients under the age of 6 years) and patients who are immunocompromised or at risk of infective endocarditis (due to the risk of bacteraemia). Finally, the tetanus status of the child should be checked and managed accordingly.

Hans K Antov,

DCT2 in Oral and Maxillofacial Surgery,

Pinderfields Hospital, Wakefield.

Email: hansantovayahoo.co.uk

\section{REFERENCES}

1. Cope AL, Wood F, Francis NA, Chestnutt IG. Patients' reasons for consulting a GP when experiencing a dental problem: a qualitative study. Br J Gen Pract 2018; DOI: https://doi.org/10.3399/ bjgp18X699749.

2. Andersson L, Andreasen J, Day P, et al. International Association of Dental Traumatology guidelines for the management of traumatic dental injuries: 2 . Avulsion of permanent teeth. Dent Traumatol 2012, 28(2): 88-96.

3. Rosenberg H, Rosenberg H, Hickey M. Emergency management of a traumatic tooth avulsion. Ann Emerg Med 2011; 57(4): 375-377.

4. Beech N, Tan-Gore E, Bohreh K, Nikolarakos D. Management of dental trauma by general practitioners. Aust Fam Physician 2015; 44(12): 915-918.

DOI: https://doi.org/10.3399/bjgp19X700973 